\title{
COMUNICACIÓN
}

\section{DETERMINACIÓN DE ANTICUERPOS CONTRA EL VIRUS DE LA ENFERMEDAD DE NEWCASTLE EN PSITÁCIDAS EN CAUTIVERIO EN EL PARQUE DE LAS LEYENDAS}

\author{
Claudia Shimabukuro I. ${ }^{1}$ y Eliana Icochea D'A. ${ }^{2}$
}

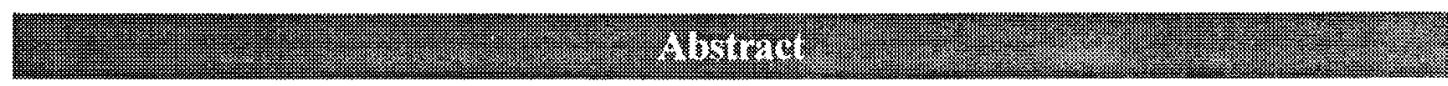

Sera from 255 apparently normal birds pertaining to 16 species of the Psittaciformes order, at Parque de las Leyendas Zoo in Lima were tested for the presence of Newcastle Disease antibodies. The hemagglutination-inhibition test was used for detecting antibodies against Paramyxovirus serotype 1. All of the birds tested negative, suggesting that they have not been exposed to the Newcastle Disease virus and did not comprise a Paramyxovirus- 1 reservoir at the moment that this study was done.

Key words: Newcastle Disease, Paramyxovirus 1, Psittaciformes.

Palabras clave: Enfermedad de Newcastle, Paramixovirus 1, Psitaciformes

La enfermedad de Newcastle (ENC) es causada por el Paramyxovirus-1 (PMV1) o virus de la enfermedad de Newcastle (VEN), perteneciente a la familia Paramyxoviridae subfamilia Paramyxovirinae, género Rubulavirus. El VEN es conocido por el riesgo que representa para la industria avícola y otras especies de aves ya que posee un amplio rango de hospederos (Alexander, 1997; Clubb, 1986; Cubas, 1993; Gerlach, 1984; King, 1999).

Esta enfermedad fue descrita por primera vez por Doyle en 1926, como una enfermedad vírica fatal de las aves domésticas que apareció cerca de Newcastle-upon-Tyne, Inglaterra; también se describió en el mismo año en Java y Corea. Posteriormente se diseminó y llegó a Sudamérica a mediados de 1950 (Cubas, 1993; Steiner $y$ Davis, 1985). Esta enfermedad ha sido reportada al me-

\footnotetext{
I Práctica privada

2 Laboratorio de Patología Aviar-FMV-UNMSM. E.mail:dl70022@unmsm.edu.pe
}

nos en 236 especies de aves, aunque con diversos grados de patogenicidad, ya que una cepa del VEN que causa una severa enfermedad en un tipo de aves puede causar una infección subclínica en otras.

Las aves afectadas clínicamente pueden desarrollar casi cualquier combinación de enfermedad moderada a severa involucrando a los sistemas respiratorio, gastrointestinal o nervioso (Ritchie y Carter, 1995). Los loros Amazonas (Amazona sp.) y conures son altamente susceptibles, en comparación a los guacamayos (Ara sp.) y periquitos en los que los signos nerviosos son raramente observados. El período de incubación en psitácidas es de 3 a 16 días (Cubas, 1993). La producción de anticuerpos humorales también varía según los grupos taxonómicos e individualmente. Los títulos de anticuerpos para la prueba de inhibición de la hemaglutinación (HI) en psitaciformes puede ser bajo en loros del género Amazonas (1:8 a 1:64) mientras que las cacatúas alcanzan títulos de 1:320. Las aves inmunes pueden actuar como portadores y eliminar el virus en forma intermitente. 
Los portadores más comunes incluyen aves acuáticas silvestres, Psitaciformes, algunos Passeriformes y Strigiformes (Gerlach, 1994).

Se han reportado brotes de la ENC a nivel mundial en parques de aves exóticas, cuarentenarias, colecciones privadas de aves, parques zoológicos y centros dedicados al comercio de aves (Altman et al., 1997; Brugh y Beard, 1983; Clubb et al., 1980). El paramixovirus-1 ha sido aislado de aves originarias de países sudamericanos y centroamericanos, constituyendo un reservorio de la enfermedad y fuente de difusión del virus (Fowler, 1978; Gerlach, 1984; Nilsson, 1981; Schmidt, 1993). El gran brote de la enfermedad ocurrido en Estados Unidos en 1971 en California se le relacionó a aves mascotas de importación, reportándose el aislamiento del virus en un loro cabeza amarilla mexicano (Amazona ochrocephala) (Nilsson, 1981).

Para reducir el riesgo de introducción de la enfermedad a través de la importación de aves exóticas, Estados Unidos y el Reino Unido establecieron programas de cuarentena aviar en 1974 y 1976, respectivamente (Cubas, 1993). Sin embargo, a pesar de que existe dicho control, el contrabando de aves continúa y se reportan casos de la enfermedad, especialmente en loros del género Amazona por ser populares como mascotas (Altman et al., 1997; Van Der Heyden, 1992).

En el Perú, entre los años 1983 a 1992, la ENC no representaba mayor problema para la avicultura; pero a partir del año 1994 empezaron a suscitarse cases severos de la enfermedad que continuaron en el año 1995, a tal punto que se modificó el esquema de vacunación de pollos de carne y pollitas de postura utilizándose la cepa vacunal La Sota y vacunas inactivadas en suspensión oleosa. De los casos ocurridos en 1994 en Lima y Arequipa, las cepas fueron identificadas en el Central Veterinary Diagnostic Laboratory de Weybridge, Inglaterra, donde determinaron que se trataba de cepas velogénicas viscerotrópicas para pollos de tipo A en el caso de Arequipa y de tipo B para el caso de Lima, lo cual significa que no fue el mismo tipo de virus que se diseminó sino un brote diferente. Esto indicaría que existe un problema de reservorios del virus que hay que tener en cuenta en la epidemiología de la ENC en el Perú (Icochea, 1996, comunicación personal).

Pese a la gran variedad de aves psitácidas que existe en nuestro país y al aumento de zoocriaderos con fines comerciales o culturales, hay pocos estudios sobre la susceptibilidad de estas aves a la ENC, así como las especies que pueden estar actuando como reservorios y propagadores de la enfermedad. Por la posibilidad que la enfermedad sea endémica en las poblaciones de psitácidas en los trópicos (Cubas, 1993), el presente estudio tuvo como objetivo evaluar la presencia de anticuerpos contra el paramixovirus-1 mediante la prueba de inhibición de la hemaglutinación en psitácidas del zoológico Parque de Las Leyendas.

El estudio se realizó en 255 aves del orden psitaciformes, correspondientes a 5 géneros y 16 especies mantenidas en cautiverio en el zoológico Parque de Las Leyendas de Lima, tal como se muestra en el Cuadro 1.

Las aves fueron capturadas con mallas, inmovilizadas manualmente y se colectó un mínimo de $0.8 \mathrm{ml}$ de sangre de la vena braquial o yugular. Las muestras obtenidas se centrifugaron en el tópico del hospital del zoológico para separar el suero, los cuales se guardaron en viales estériles y fueron congelados hasta el momento del procesamiento.

La prueba de HI (microtécnica) descrita por Alexander (1989) fue utilizada para la detección de anticuerpos, la cual fue realizada en el Laboratorio de Patología Aviar de la Facultad de Medicina Veterinaria de la Universidad Nacional Mayor de San Mar$\cos$.

En ningún animal de los evaluados se puedo detectar anticuerpos contra el VEN. 
Cuadro 1. Aves psitaciformes evaluadas para la detección de anticuerpos contra el Virus de la Enfermedad de New Castle (VEN), procedentes del Zoológico Parque de Las Leyendas.

\begin{tabular}{lc}
\hline Nombre común (Nombre científico) & $\begin{array}{c}N^{\circ} \text { de animales } \\
\text { por especie }\end{array}$ \\
\hline Papagayo rojo y amarillo (Ara macao) & 13 \\
Papagayo rojo y verde (Ara chloroptera) & 12 \\
Papagayo azul y amarillo (Ara ararauna) & 18 \\
Papagayo militar (Ara militaris) & 07 \\
Papagayo cabeza azul (Ara couloni) & 13 \\
Papagayo frente castaña (Ara severa) & 02 \\
Loro farinosa (Amazona farinosa) & 20 \\
Loro cara amarilla (Amazona amazonica) & 10 \\
Loro frente amarilla (Amazona ochrocephala) & 31 \\
Loro espalda roja (Amazona festiva) & 11 \\
Loro cabeza azul (Pionus menstruus) & 33 \\
Loro frente roja (Aratinga wagleri) & 03 \\
Loro máscara roja (Aratinga erithrogenys) & 24 \\
Loro de mitra roja (Aratinga mitrata) & 03 \\
Loro ojo blanco (Aratinga leucophtalmos) & 05 \\
Perico frente amarilla (Brotogeris sanctithomae) & 50 \\
\hline Total & 255 \\
\hline
\end{tabular}

En el Perú, la ENC es prevalente, siendo frecuente los brotes en pollos de carne y de postura en algunas zonas. Las cepas existentes son de alta patogenicidad y durante los últimos meses los organismos de gobierno están preocupados en la erradicación de las formas velogénicas de la ENC. Para lograr este objetivo no sólo es necesario el control de la enfermedad a nivel de la avicultura industrial sino también identificar y eliminar las posibles fuentes de contaminación.

Existen reportes en diferentes países que demuestran la importante condición de reservorios de este virus de las aves del orden psitaciformes (Clubb, 1986; Clubb et al., 1980; Cubas, 1993; Panigraphy et al., 1993; Schmidt, 1993; Senne y Pearson, 1983; VanDerHeyden, 1992), aves que concentra en gran número el zoológico Parque de Las Leyendas de Lima, proveniendo la mayor parte de ellas de zonas tropicales, a quienes se les ha atribuido de ser endémicas de esta enfermedad (Clubb, 1986; Cubas, 1993). Sin embargo, en el presente estudio, la evaluación de 255 aves pertenecientes a 16 especies del orden psitaciformes de este zoológico resultaron negativas a anticuerpos contra el VEN por la prueba de HI, resultados que coinciden con el estudio realizado por Gilardi, et al. (1995), quienes evaluaron muestras de 17 aves psitácidas de la Reserva del Manu en Madre de Dios, encontraron resultados negativos a este agente a la misma prueba. En otro estudio realizado en Perú, en Tambopata, se muestrearon 27 aves psitácidas de vida libre y criadas a mano, arrojando resultados negativos para la detección de anticuerpos contra PMV-1 mediante la prueba de HI (Karesh, et al., 1997).

Estos hallazgos permiten concluir que las especies de psitácidas del zoológico Parque de Las Leyendas de Lima evaluadas no presentan anticuerpos contra el VEN a la prueba de HI, sugiriendo que dichas aves no estuvieron expuestas al virus; por lo que, aparentemente, no constituyen un reservorio del 
VEN en el país. Es difícil interpretar los reportes de estaciones de cuarentena y casos clínicos de aves producto del comercio ilegal en Estados Unidos y aplicarlos a las poblaciones de aves en estado silvestre, ya que la infección podría darse durante el transporte $\mathrm{y}$ alojamiento y no necesariamente provenir del estado natural. Sin embargo, hay que tener presente que está comprobada la resistencia que pueden tener algunos especímenes a manifestar signos clínicos de la enfermedad después de la infección con el VEN, convirtiéndose en portadores del virus, por lo que es importante evaluar serológicamente al resto de la población aviar de este zoológico y a las aves nuevas que ingresan a cuarentena para mantener a la población del zoológico Parque de Las Leyendas libre de este agente y que, conjuntamente con el virus de influenza aviar, son causantes de las enfermedades infecciosas más importantes en aves, estando incluidas dentro de la Lista $\mathrm{A}$ de las enfermedades reportables por la Oficina Internacional de Epizootias.

\section{Uiterturicterda}

1. Alexander, D. 1989. Newcastle Disease, In: A laboratory manual for the isolation and identification of avian pathogens; 3th ed. p. 114-120. AAAP Hunt Publishing Company.

2. Alexander, D.J. 1997. Newcastle Disease and other Paramyxovirus infections, En: Diseases of Poultry, $10^{\text {the }}$ d. p.541569. Ed. Calnek BW, et al, Ames, Iowa State University Press.

3. Altman, R.; S. Clubb; G. Dorrestein y K. Quesenberry. 1997. Avian medicine and surgery, p. 304-305, 354-355. W.B.Saunders, Philadelphia.

4. Brugh, M. y C.W., Beard. 1983. Atypical disease produced in chickens by Newcastle Disease virus isolated from exotic birds. Avian Dis 28:482-488.

5. Clubb, S.L. 1986. Velogenic Viscerotropic Newcastle Disease. En: Zoo and Wild Animal Medicine. Ed. Fowler ME, $2^{\text {nd }}$ ed, p. 222-225. W.B. Saunders,
Philadelphia.

6. Clubb, S.L.; B.M. Levine y D.L. Graham. 1980. An outbreak of viscerotropic velogenic Newcastle disease in pet birds. Proc Assoc Zoo Vet. p. 105-109.

7. Cubas, Z.S. 1993. Natural diseases of free-ranging birds in South America. En: Zoo and wild animal medicine : current therapy. $3^{\text {th }}$ ed. p.166-168. Ed. Fowler ME, W.B. Saunders, Philadelphia.

8. Fowler, M.E. 1978. Zoo and wild animal medicine. p. 373-374. W.B. Saunders, Philadelphia.

9. Gerlach, H. 1984. Viral diseases in pet birds. Vet Clin North Am Small Anim Pract 14:299.

10. Gerlach, H. 1994. Viruses. En: Avian medicine, principles and application. p.920-925, Ed. Ritchie B, Harrison GJ, Harrison LR, Wingers Publishing, Lake Worth, Florida.

11. Gilardi, K.; L.J. Lowenstine; J.D. Gilardi; J. Gilardi y Ch. Munn. 1995. A survey for selected viral, chlamidial, and parasitic diseases in wild duskyheaded parakeets (Aratinga weddeli) and tui parakeets (Brotogeris sanctithomae) in Peru. J Wildl Dis 31(4):523-528.

12. Karesh, W.; A. Del Campo; E. Brasselton; H. Puche y R. Cook. 1997. Health evaluation of free-ranging and hand-reared macaws (Ara sp) in Peru. $\mathbf{J}$ Zoo Wildl Med 28(4): 368-377.

13.King, D. 1999. Enfermedad de Newcastle. En XVI Congreso latinoamericano de avicultura. p.56-62.

14. Nilsson, G. 1981. The Bird Business, a study of the commercial cage bird trade, 2ed. p.13-22.

15. Panigraphy, B.; D.A. Senne; J.E. Pearson; M.A. Mixson y D.R. Cassidy. 1993. Ocurrence of Velogenic Viscerotropic Newcastle Diseases in pet and exotic birds in 1991. Avian Dis 37:254-258.

16. Ritchie, B. y K. Carter. 1995. Avian Viruses, p.253-283, Wingers Publishing, Lake Worth, Florida.

17. Schmidt, R.E.1993. Psittacine birds as reservoirs of serious diseases. En: Zoo 
and Wild Animal Medicine: current therapy. $3^{\text {th }}$ ed. p.245. Ed. Fowler ME, W.B. Saunders, Philadelphia.

18. Senne, D.A. y J.E. Pearson. 1983. Virus isolations from pet birds submitted for importation into the United States. Avian Dis 27(3):731-744.
19. Steiner, Ch.V. y R.B. Davis. 1985. Patología de las aves enjauladas, temas seleccionados. p.121-124. Ed Acribia, Zaragoza.

20. VanDerHeyden, N. 1992. Velogenic Viscerotropic Newcastle disease in three Amazon chicks. Proc Assoc Avian Vet . 158-161. 